\title{
RELATIONSHIP OF BALL MUSCLE POWER TOWARDS SPIKE VOLYBALL SKILLS
}

\section{HUBUNGAN POWER OTOT TUNGKAI TERHADAP KETERAMPILAN SPIKE BOLA VOLI}

Delfi Marzah ${ }^{1}$, Feby Elra Perdima ${ }^{2}$

${ }^{1}$ Study Program Departemen Phsycal Education Study Program, Universitas Dehasen Bengkulu, Indonesia

${ }^{2}$ Departemen Phsycal Education Study Program, Universitas Dehasen Bengkulu, Indonesia
Corresponding Author: perdima.elra@gmail.com

\section{How to Cite : \\ ARTICLE HISTORY \\ Received [24November 2020] \\ Revised [2 December 2020] \\ Accepted [26 December 2020]}

Marzah. D., Perdima. E.F. (2020). RELATIONSHIP OF BALL MUSCLE POWER TOWARDS SPIKE VOLYBALL SKILLS, Hanoman Journal, 1(2). 2020. DOI: https://doi.org/10.37638/hanoman.1.2.63-71

\section{ABSTRAK}

Kata Kunci :

Kekuatan otot tungkai, spike, bola voli

Keywords:
leg muscle power, spike,
volleyball

leg muscle power, spike,
volleyball

under the $C C-B Y-S A$ license

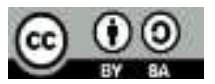

Penelitian ini bertujuan untuk mengetahui hubungan power otot tungkai terhadap keterampilan spike bola voli pada siswa kelas X SMA Negeri 1 Ulu Musi Kabupaten Empat Lawang. Metode yang dipakai adalah metode diskriptif korelasional, karena pada dasarnya penelitian ini bertujuan untuk mengetahui hubungan antara variabelvariabel.Instrumen Pengambilan data penelitian dilakukan dengan cara mengukur power otot tungkai dilakukan dengan tes Vertical Jump, Selanjutnya keterampilan Spike dilakukan dengan Spike. Hasil analisis data menunjukkan bahwa hipotesis yang diajukan dapat diterima, terdapat hubungan yang positif antara kedua variabel yaitu

sebesar 0,977 bernilai positif, artinya semakin besar skor yang diperoleh maka semakin kuat hubungan antara kedua variabel. Uji keberartian koefisien korelasi tersebut dilakukan dengan cara harga $r_{\text {hitung }}$ dengan $r_{\text {tabel }}$ pada $\alpha=5 \%$ dengan $N=24$ diperoleh $r_{\text {tabel }}$ sebesar 0,404 Karena koefisien korelasi antara $r_{x . y}=0,97>r_{(0,5)(24)}=$ 0,404 berarti hubungan Power otot tungkai terhadap keterampilan Spike siswa SMA Negeri 1 Ulu Musi adalah signifikan. Dengan demikian hipotesis yang berbunyi "ada hubungan yang kuat antara power otot tungkai terhadap keterampilan Spike siswa SMA Negeri 1 Ulu Musi", diterima. Artinya ada hubungan kekuatan otot tungkai terhadap keterampilan Spike siswa SMA Negeri 1 Ulu Musi.

\begin{abstract}
This study aims to determine the correlation between leg muscle power to volleyball spike skills in class X SMA Negeri 1 Ulu Musi, Empat Lawang. The method used is a descriptive correlational method, because basically this study aims to determine the relationship between variables. The research data collection instrument was carried out by measuring the power of the leg muscles using the Vertical Jump test, then the Spike skill was performed with the Spike. The results of data analysis indicate that the hypothesis proposed is acceptable, there is a positive relationship between the two variables, namely of 0.977 is positive, meaning that the greater the score obtained, the stronger the relationship between the two variables. The test for the significance of the correlation coefficient was carried out by means of the value $r$ count with $r$ table at $\alpha=5 \%$ with $N=24$ obtained $r$ table of 0.404 because the correlation coefficient between rx.y $=0.97>r(0.5)(24)=0.404$ means the correlation between the power of leg muscles on the Spike skills of SMA Negeri 1 Ulu Musi students is significant. Thus, the hypothesis which says "there is a strong correlation between leg muscle power on the Spike skills of SMA Negeri 1 Ulu Musi students", is accepted. This means that there is a correlation between leg muscle strength and the Spike skills of SMA Negeri 1 Ulu Musi students.
\end{abstract}

\section{PENDAHULUAN}

Pendidikan merupakan usaha sadar dan terencana dari sebagian manusia dalam memenuhi kebutuhan psikologisnya. Pendidikan mempunyai peranan penting dalam kehidupan. Pendidikan 
yang ada di sekolah salah satunya adalah pendidikan jasmani. Pendidikan jasmani merupakan proses dalam perencanaan, pengarahan sumber daya pendidikan melalui aktifitas gerak dan olahraga yang terpilih untuk mencapai tujuan pendidikan secara efektif dan efesien dalam kebugaran jasmani.

Pada hakikatnya pendidikan jasmani dan olahraga merupakan proses pendidikan yang memanfaatkan aktifitas fisik (jasmani) dan olahraga untuk menghasilkan perubahan dalam individu, baik dalam hal fisik, mental dan emosional. Dalam perkembanganya olahraga pada saat ini sudah berkembang dengan cepat, hal ini dapat dilihat dari masyarakat yang sudah semakin menyadari akan pentingnya aktivitas berolahraga.

Adapun keolahragaan terkhusus yang mengarah ke prestasi menjadi suatu alasan seseorang dalam berolahraga. Sejalan dengan perkembangannya, olahraga merupakan daya penggerak motorik serta aktifitas fisik yang terkoordinasi dengan baik dari tingkat anak-anak, remaja bahkan ke tingkat dewasa.

Tujuan pendidikan jasmani pada hakikatnya yaitu memberikan kesempatan kepada anak untuk mempelajari berbagai kegiatan guna membina sekaligus mengembangkan potensi anak yang meliputi aspek penilaian yaitu, afektif, kognitif dan psikomotor. Hal tersebut seiring dengan isi Undang-Undang Republik Indonesia Nomor 3 tahun 2005 Pasal 1 ayat 3 tentang Sistem Keolahragaan Nasional yang menyatakan bahwa "Olahraga adalah segala kegiatan yang sistematis untuk mendorong, membina, serta mengembangkan potensi jasmani, rohani, dan sosial".

Olahraga merupakan salah satu faktor utama yang dapat mempengaruhi kebugaran dan kesehatan, serta kebutuhan pokok yang paling utama yang tidak pernah bisa ditukar dengan apapun. Oleh karena itu setiap orang tentu menginginkan hidup sehat dan ingin selalu tampak sehat, bugar, tanpa ada suatu penyakit.

Hal ini dapat dicapai melaui kegiatan pembelajaran yang direncanakan secara matang dengan berpedoman pada ilmu kependidikan. Olahraga merupakan media untuk mendorong pertumbuhan fisik, keterampilan motorik, pengetahuan dan penalaran. Olahraga juga merupakan merupakan kebutuhan bagi setiap orang, karena semua orang pasti ingin sehat, tidak seorangpun yang ingin sakit atau terganggu kesehatannya.

Peningkatkan prestasi perlu diadakan karena adanya dorongan dari dukungan beberapa pihak, di sekolah salah satunya yang sangat mempengaruhi dalam meningkatkan prestasi adalah peran seorang guru. Dengan peningkatan olahraga prestasi yang sangat mendesak, mengingat prestasi olahraga juga merupakan prestasi sekolah-sekolah. Maka sekolah-sekolah pun berlomba-lomba dalam peningkatan prestasi guna menjaga nama baik sekolah tersebut.

Olahraga juga mempunyai peranan yang sangat penting untuk membantu tercapainya kebugaran jasmani. Pembekalan pengalaman belajar pendidikan jasmani diarahkan untuk membina pertumbuhan faktor fisik dan pengembangan mental yang lebih baik, sekaligus membentuk pola hidup yang sehat. Dari beberapa penjelasan yang telah diuraikan, serta kaitanya pendidikan jasmani yang ada di SMA Negeri 1 Ulu Musi Kabupaten Empat Lawang, perlu adanya peningkatan kembali mengenai keterampilan spike (smash)

Hal yang paling mendasar yang berkaitan dengan faktor pemahaman pembelajaran keterampilan dasar spike bolavoli yang kurang keras dan kurang tepat serta power otot tungkai yang masih kurang kuat. Hal ini dikarenakan pada saat observasi pembelajaran yang dijalani siswa banyak yang melakukan spike masih terlalu lemah dan salah dalam melakukan gerakannya. Keterampilan spike dibutuhkan ketepatan dan keras dalam memukul.

Berdasarkan penjelasan mengenai teknik dasar yang ada di atas, teknik spike merupakan salah satu teknik yang harus dikuasi oleh setiap siswa. Spike merupakan salah satu teknik yang selalu digunakan pemain dalam mendapatkan point dan mematikan pergerakan permainan lawan. Setiap pemain dalam melakukan spike harus selalu ditingkatkan guna untuk menghasilkan point yang banyak dalam suatu permainan. 
Aktivitas olahraga dapat disebutkan sebagai motor pengerak dalam setiap aktivitas gerak yang dilakukan guna untuk mendapatkan hasil yang ingin dicapai. Maka dari itu olahraga bolavoli sangat membutuhkan power otot tungkai yang baik pada waktu melakukan spike. Power dalam melakukan melakukan spike memiliki faktor penentu pada saat mendapatkan point dengan gerakan tepat dan akurat.

\section{LANDASAN TEORI}

Bolavoli merupakan permainan olahrga beregu yang berasal dari amerika serikat. Tiap regu bolavoli terdiri atas enam orang pemain. Diciptakan oleh Wiliam G Morgan pada tahun 1895 dia adalah seorang pembina pendidikan jasmani dari Amerika Serikat mula-mula permainan bola voli diberi nama Mintonette. Kemudian Wiliam G Morgan melanjutkan idenya untuk mengembangkan permainan tersebut agar menjadi cabang olahraga yang dipertandingkan, nama permainan kemudian dirubah menjadi Volley Ball.

Permainan bolavoli termasuk ke dalam permainan bola besar. Bolavoli masuk ke indonesia pada masa pendudukan Jepang. Perkembangan bolavoli di Indonesia cukup baik. Bangsa Indonesia sudah pernah merajai di tingkat ASEAN. Walaupun demikian di tingkat nasional, kekuatan bolavoli masih berada di Pulau Jawa belum merata di setiap provinsi.

Seiring berjalannya waktu, bolavoli merupakan olahraga yang sangat populer. Bolavoli di Indonesia sudah dikenal sejak tahun 1928 dibawah oleh guru-guru belanda yang mengajar di sekolah-sekolah lanjutan, \kemudian berkembang di Indonesia pada tanggal 22 Januari 1955 di Jakarta sekaligus diresmikan dan berdirinya PBVSI (Persatuan Bola Voli Seluruh Indonesia).

Permainan bolavoli dimainkan oleh dua regu yang saling berhadapan dan masing-masing regu terdiri enam orang pemain. Hidayat (2017:15) menjelaskan "indikator lain yang bisa menunjukkan bahwa bolavoli merupakan olahraga yang cukup digemari adalah dengan tingginya animo penonton pada saat digelarnya pertandingan bolavoli". Permainan bolavoli dilakukan dengan cara bola di oper sebanyak-banyaknya tiga kali.

Beutelstahl menambahkan (2015:65) Volleyball merupakan "suatu cabang olahraga yang ditandai dengan peraturan-peraturan yang begitu khas dan kukuh". Permainan bolavoli merupakan suatu permainan cabang olahraga berkembang yang sangat digemari oleh semua lapisan masyarakat, baik dari anak-anak sampai orang tua, laki-laki maupun perempuan, masyarakat pedesaaan sampai masyarakat kota.

Bolavoli adalah salah satu permainan yang sangat banyak digemari masyarakat karena selain tergolong cabang olahraga prestasi, juga lebih dominan mengarah ke unsur olahraga rekreasi yang berdampak kesenangan. Permainan bolavoli adalah olahrga yang selalu berkembang sesuai dengan kemajuan jaman, baik dilihat dari segi kualitas yang dilakukan ataupun penguasaan teknik yang dimiliki oleh para pemain bolavoli itu sendiri (Rohendi dan Etor, 2018:14).

Adapun menurut Erianti (2004:2) menjelaskan "ide dasar permainan bolavoli itu adalah memasukkan bola ke daerah lawan melewati suatu rintangan berupa tali atau net. Tujuan awal dari permainan bolavoli ini adalah untuk mengisi waktu luang atau sebagai selingan setelah lelah bekerja. Namun berkembang ke arah tujuan-tujan yang lain, untuk memperluas pergaulan, kesehatan, bahkan ketingkat prsetasi. Seperti misalnya untuk mencapai prestasi yang tinggi dalam meningkatkan prestasi diri, mengharumkan nama sekolah, daerah, bangsa bahkan negara.

Permainan bolavoli juga ditujukan untuk memelihara dan meningkatkan kesegaran jasmani. Di samping meningkatkan kesegaran jasmani yang merupakan unsur kondisi fisik, taktik dan mental, mengembangkan mutu prestasi permainan bolavoli merupakan salah satu unsur yang menentukan menang atau kalah suatu tim di dalam pertandingan.

Adapun manfaat dalam olahraga bolavoli ini diantaranya menyenangkan juga dapat mempererat tali persaudaraan dalam keluarga, sanak saudara, antar tetangga dan lain sehingga tercipta suasana santai dan rukun. Seperti dijelaskan dalam peraturan permainan bolavoli bahwa, 
tujuan dari permainan bolavoli adalah melewatkan bola di atas net agar dapat jatuh menyentuh lantai lapangan lawan dan untuk mencegah usaha yang sama dari lawan.

Untuk dapat bermain bolavoli siswa harus dapat menguasai teknik dasar agar permainan bolavoli berjalan atau berlangsung dengan baik, lancar dan teratur, maka para pemain dituntut harus menguasai unsur-unsur dasar permainan, yaitu teknik dasar bermain bolavoli.

Adapun macam-macam teknik-teknik dasar permainan bolavoli menurut Yoenoes (2009:79) meliputi :

1) Service

2) Passing

3) Umpan (set-up)

4) Smash (spike)

5) Bendungan (block)

\section{Spike}

Salah satu teknik yang harus dikuasai seorang pemain atau siswa adalah spike. Spike merupakan usaha tim menyerang dengan memukul ke dalam lapangan lawan. Menurut Rohendi (2018:138) "spike merupakan pukulan yang kuat dan diarahkan degan keras yang digunakan untuk mengembalikan bola ke dalam lapangan lawan. Adapun tujuan dari keterampilan ini adalah untuk mematikan pergerakan lawan dengan memukul bola dengan keras dalam mendapatkan point.

Ada beberapa hal yang harus diingat di dalam penguasaan teknik permainan bola voli menurut Erianti (2004:142), yakni sebagai berikut:

1. Permainan bola voli adalah pemain tempo yang cepat, sehingga waktu untuk memainkan bola sangat terbatas dan tidak menguasai teknik dengan baik (sempurna) akan memungkinkan terjadinya kesalahan-kesalahan yang lebih besar.

2. Hukuman terhadap kesalahan teknik memantulkan dan memukul bola dalam peraturan permainan bola voli cukup dominan jika dibandingkan dengan cabang olahraga lainnya.

3. Regu yang saling bertanding dipisahkan oleh net sehingga tidak pernah terjadi kontak badan antara pemain yang saling berlawanan, hal ini memudahkan wasit menguasai kesalahan teknik yang dilakukan para pemain.

4. Dalam mengembangkan dan menerapkan tatik-taktik yang tinggi tentunya terlebih dahulu harus memiliki penguasaan teknik yang baik dan sempurna.

\section{Power Otot Tungkai}

Otot merupakan alat penggerak aktif karena mampu berkontraksi dan berfungsi menggerakkan organ-organ tertentu dalam tubuh. Daya ledak atau power menurut McGinnis (2010:136) adalah hasil kekuatan yang diterapkan oleh suatu otot yang cepat dengan kontraksi yang kuat menjadi lebih powerfull (tenaga penuh) dibandingkan dengan kekuatan otot yang menerapakan pelan-pelan. Perbedaan karakter otot terletak pada kemampuannya berkontraksi. Aksi otot ini biasanya dikenal sebagai kontraksi otot.

Menurut Rika (2015:42-43), "Otot memiliki tiga kemampuan khusus, yaitu:

1. Kontraktibilitas: Kemampuan untuk berkontrkasi/memendek

2. Ekstensibilitas: Kemampuan untuk melakukan gerakan kebalikan dari gerakan yang ditimbulkan saat kontraksi

3. Elastisitas: Kemampuan otot untuk kembali pada ukuran semula setelah berkontraksi. Saat kembali pada ukuran semula otot disebut dalam keadaan relaksasi.

Power otot adalah komponen yang sangat penting untuk meningkatkan kondisi fisik secara keseluruhan. Power otot merupakan salah satu unsur kondisi fisik yang memiliki peranan penting dalam kegiatan olahraga khusunya olahraga futsal, baik sebagai unsur pendukung dalam suatu gerak tertentu maupun unsur utama dalam upaya pencapaian teknik gerak yang sempurna. 


\section{METODE PENELITIAN}

Menurut Subagyo (2015:2) "Metode penelitian merupakan suatu cara atau jalan untuk memperoleh kembali pemecahan terhadap segala permasalahan". Metode penelitian ini mengunakan dua variabel dimana variabel bebasnya adalah power otot tungkai sebagai variabel (X), sedangkan variabel terikatnya adalah keterampilan spike sebagai (Y). Metode penelitian yang digunakan dalam penelitian ini adalah dengan menggunakan metode korelasional (correlational research).

Teknik analisis dalam penelitian ini adalah analisis kuantitatif yang digunakan untuk membahas masalah yang dinamis dengan menggunakan data yang berupa angka-angka. Data yang diperoleh akan dianalisis secara statistik dengan uji korelasi berguna untuk memilih variabel bebas yang memang didukung oleh data. Untuk mengetahui interaksi kekuatan otot tungkai terhadap keterampilan spike pada permainan bolavoli di SMA Negeri 1 Ulu Musi Kabupaten Empat Lawang.

\section{HASIL}

\section{Hasil Tes Power Otot Tungkai (X)}

Dari hasil pengukuran power otot tungkai yang dilakukan terhadap siswa SMA Negeri 1 Ulu Musi didapat skor tertinggi 51 dan skor terendah 33 berdasarkan data tersebut rata-rata hitung (mean) 43.29. Langkah awal tentukan banyak kelas dengan rumus $1+3.3 \log 24$ (sampel) $=5.554$, dapat di bulatkan menjadi 6 , dan mencari panjang kelas dengan rumus nilai tertinggi dikurang nilai terendah di bagi banyak kelas adalah $51-33=18: 6=3$. Distribusi kategori power otot tungkai yang dilakukan terhadap siswa SMA Negeri 1 Ulu Musi dapat dilihat pada tabel berikut :

Tabel 1. Distribusi Frekuensi Power otot tungkai

\begin{tabular}{|c|c|c|c|}
\hline No & Kelas Interval & Frekeunsi Absolut & Frekuensi Relatif\% \\
\hline 1. & $33-36$ & 5 & 20.83 \\
\hline 2. & $37-40$ & 2 & 8.33 \\
\hline 3. & $41-44$ & 6 & 25.00 \\
\hline 4. & $45-48$ & 5 & 20.83 \\
\hline 5. & $49-52$ & 6 & 25.00 \\
\hline 6. & $53-56$ & 0 & 0.00 \\
\hline
\end{tabular}

Dari tabel 1. di atas dapat disimpulkan bahwa dari 24 siswa sebanyak 5 orang siswa (20.83\%) memiliki kategori nilai 33-36. sebanyak 2 orang siswa $8.33 \%$ memiliki kategori nilai 37-40. Sebanyak 6 siswa 25\% memiliki kategori nilai $41-44$. Sebanyak 5 orang siswa $20.83 \%$ memiliki kategori nilai 45-48. Sebanyak 6 orang siswa 25\% memiliki kategori nilai 53-56. dapar dilihat histrogram di bawah ini 


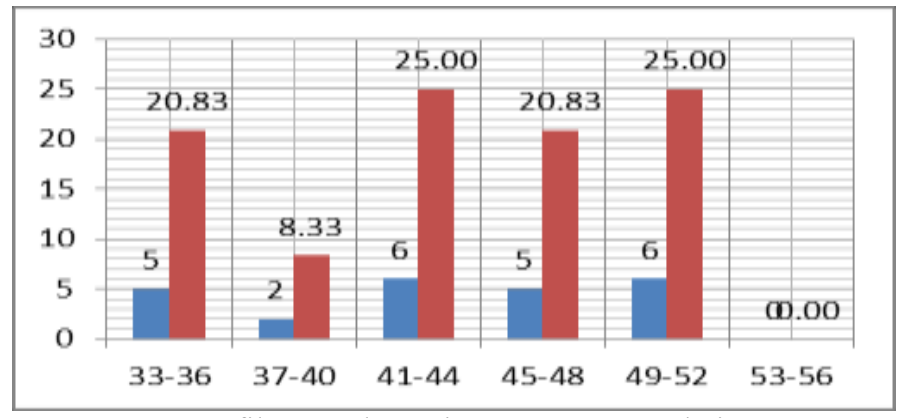

Grafik 1. Frekuensi Power otot tungkai

\section{Hasil Tes Keterampilan Spike (Y)}

Dari hasil pengukuran Spike yang dilakukan terhadap siswa SMA Negeri 1 Ulu Musi terdapat t-skor tertinggi 15 dan skor terendah 5, berdasarkan data tersebut rata-rata hitung (mean) 10.7 Langkah awal tentukan banyak kelas dengan rumus $1+3.3 \log 24$ (sampel) $=5.554$, dapat di bulatkan menjadi 6 , dan mencari panjang kelas dengan rumus nilai tertinggi dikurang nilai terendah di bagi banyak kelas adalah 15-5=10:6=1.6 di bulatkan jadi 2 . Distribusi kategori keterampilan Spike yang dilakukan siswa SMA Negeri 1 Ulu Musi dapat dilihat pada tabel berikut :

Tabel 2. Distribusi Frekuensi Hasil Tes Keterampilan Spike (Y).

\begin{tabular}{|c|c|c|c|}
\hline No & Kelas Interval & Frekeunsi Absolut & Frekuensi Relatif\% \\
\hline 1. & $5-7$ & 4 & 16.67 \\
\hline 2. & $8-10$ & 6 & 25.00 \\
\hline 3. & $11-13$ & 9 & 37.50 \\
\hline 4. & $14-16$ & 5 & 20.83 \\
\hline 5. & $17-19$ & 0 & 0.00 \\
\hline 6 & $20-22$ & 0 & 0.00 \\
\hline
\end{tabular}

. Dari tabel di atas dapat disimpulkan bahwa dari 24 siswa SMA Negeri 1 Ulu Musi. Sebanyak 4 orang siswa (16.67\%) memiliki kategori nilai 5-7. 6 orang siswa (25\%) memiliki kategori nilai $8-10.9$ orang siswa $(37.50 \%)$ memiliki kategori nilai $11-13$. 5 orang siswa $(20.83 \%)$ memiliki kategori nilai 14-16.

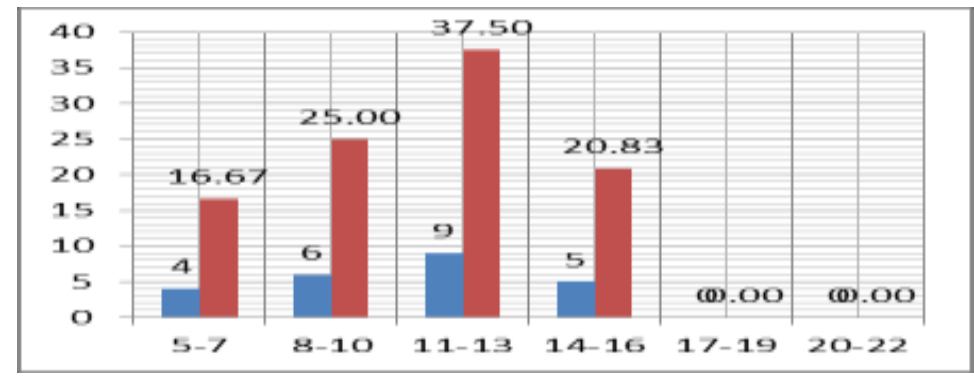

Grafik 2. Hasil Tes Keterampilan Spike (Y)

\section{Uji normalitas data}

Sebelum melakukan pengujian hipotesis yang diajukan dalam penelitian ini, maka terlebih dahulu dilakukan uji prasyarat analisis data yaitu uji normalitas data. Dalam uji normalitas data 
2723-60

ini peneliti menggunakan uji normalitas data lilliefors. Adapun hasil analisis dapat dilihat pada tabel di bawah ini :

Tabel 3. Uji Normalitas Data Variabel X dan Y

\begin{tabular}{|c|c|c|c|c|}
\hline No & Variabel & $\mathbf{L}_{\text {hitung }}$ & $\mathbf{L}_{\text {tabel }}$ & Keterangan \\
\hline 1. & Power otot tungkai & 0.1412 & $\mathbf{0 . 1 7 3}$ & Normal \\
\hline 2. & Keterampilan Spike & $\mathbf{- 0 . 1 5 5 8}$ & $\mathbf{0 . 1 7 3}$ & Normal \\
\hline
\end{tabular}

Dari tabel di atas menunjukan bahwa hasil pengujian untuk Power otot tungkai (X) skor $\mathrm{L}_{\text {hitung }} 0.1412$ dengan $\mathrm{n}=24$ sedangkan $\mathrm{L}_{\text {tabel }}$ pada taraf signifikan $5 \%$ atau 0,05 diperoleh $\mathbf{0 , 1 7 3}$. Karena $\mathrm{L}_{\text {hitung }}$ lebih kecil dari $\mathrm{L}_{\text {tabel }}$ sehingga dapat disimpulkan bahwa skor yang diperoleh dari vertical jump berdistribusi normal. Selain itu tabel tersebut di atas juga menunjukan bahwa hasil pengujian untuk keterampilan Spike $(\mathrm{Y})$ skor $\mathrm{L}_{\text {hitung }}=\mathbf{- 0 . 1 5 5 8}$ dengan $\mathrm{n}=24$, sedangkan $\mathrm{L}_{\text {tabel }}$ pada taraf signifikan $5 \%$ atau 0,05 diperoleh $\mathbf{0 , 1 7 3}$. Karena $\mathrm{L}_{\text {hitung }}$ lebih kecil dari pada $\mathrm{L}_{\text {tabel }}$ sehingga dapat disimpulkan bahwa skor yang diperoleh dari keterampilan Spike berdistribusi normal.

\section{Uji Homogenitas Data}

Uji prasyarat analisis data setelah melakukan uji normalitas data maka dilakuakan uji homogenitas data dengan menggunakan uji varians (uji F dari Hevley) dapat di lihat pada tabel berikut ini :

Tabel. 4. Uji Homogenitas Data Variabel X dan Y

\begin{tabular}{|l|l|l|l|l|l|}
\hline No & Variabel & Varians & $\mathbf{F}_{\text {hitung }}$ & $\mathbf{F}_{\text {tabel }}$ & Ket \\
\hline 1 & Power otot tungkai & $\mathbf{6 . 0 8}$ & $\mathbf{2 . 0 7}$ & $\mathbf{3 . 4 0}$ & Homogen \\
\hline 2 & Keterampilan Spike & $\mathbf{2 . 9 2}$ & & & \\
\hline
\end{tabular}

Dari tabel di atas menunjukan bahwa hasil pengujian varians untuk power otot Tungkai (X) didapat skor 6.08, sedangkan hasil pengujian varians untuk keterampilan Spike (Y) didapat skor 2.92 sehinggga didapat $\mathrm{F}_{\text {hitung }}$ dengan menggunakan uji $\mathrm{F}$ dari Hevley diperoleh skor 2.07. Sedangkan untuk nilai $\mathrm{F}_{\text {tabel }}$ dengan tarap signifikan $5 \%$ atau 0,05 adalah $=3,40$ karena $F_{\text {hitung }}$ (2.07) lebih kecil dari $F_{\text {tabel }}(3,40)$ maka data dapat disimpulkan bahwa skor yang diperoleh untuk power otot tungkai (X) terhadap keterampilan Spike (Y) memiliki data yang homogen.

\section{Hasil Uji Hipotesis}

Analisis data penelitian yang digunakan untuk menguji hipotesis terdiri atas analisis korelasi sederhana. Hipotesis dalam penelitian ini adalah "Ada hubungan yang signifikan antara Power otot tungkai terhadap keterampilan Spike pada siswa SMA Negeri 1 Ulu Musi”. Hasil uji hipotesis dengan menggunakan analisis koefisien korelasi product moment dapat dilihat pada tabel berikut ini :

Tabel 5. Koefisien Korelasi Variabel (X) Terhadap Variabel (Y).

\begin{tabular}{|c|c|c|c|}
\hline Korelasi & $\mathbf{r}_{\text {hitung }}$ & $\mathbf{r}_{\text {tabel }}$ & Keterangan \\
\hline $\mathrm{r}_{\mathrm{xy}}$ & 0,977 & 0,404 & Signifikan \\
\hline
\end{tabular}

Berdasarkan hasil analisis tersebut di atas diperoleh koefisien korelasi Power otot tungkai terhadap keterampilan Spike siswa SMA Negeri 1 Ulu Musi sebesar 0,977 bernilai positif, artinya semakin besar skor yang diperoleh maka semakin kuat hubungan antara kedua variabel. Uji keberartian koefisien korelasi tersebut dilakukan dengan cara harga $r_{\text {hitung }}$ dengan $r_{\text {tabel }}$ pada $\alpha=5 \%$ dengan $\mathrm{N}=24$ diperoleh $\mathrm{r}_{\text {tabel }}$ sebesar 0,404 Karena koefisien korelasi antara $\mathrm{r}_{\mathrm{x} . \mathrm{y}}=0,97>$ $\mathrm{r}_{(0,5)(24)}=0,404$ berarti hubungan Power otot tungkai terhadap keterampilan Spike siswa SMA Negeri 1 Ulu Musi adalah signifikan. Dengan demikian hipotesis yang berbunyi "ada hubungan 
yang kuat antara power otot tungkai terhadap keterampilan Spike siswa SMA Negeri 1 Ulu Musi", diterima. Artinya ada hubungan kekuatan otot tungkai terhadap keterampilan Spike siswa SMA Negeri 1 Ulu Musi.

\section{Pembahasan}

Berdasarkan hasil penelitian menunjukan bahwa ada hubungan yang signifikan antara kekuatan otot tungkai terhadap keterampilan Spike siswa SMA Negeri 1 Ulu Musi, dengan nilai $\mathrm{r}_{\mathrm{x} . \mathrm{y}}=0,97>\mathrm{r}_{(0,05)(24)}=0.404$. Dari hasil penelitian ini Spike merupakan salah satu teknik yang sangat penting dalam permainan bola voli karena Spike adalah suatu teknik untuk mendapatkan poin dari lawan. Karena spike adalah pukulan cepat dan kuat. Selain power otot tungkai dalam bola voli dapat disebutkan sebagai poin yang penting dalam melakukan Spike yang cepat dalam setiap aktivitas Spike

Spike yang tepat dan cepat membutuhkan latihan power otot tungkai yang terprogram dan dengan bimbingan pelatih untuk mengarahkan bagiamana dapat menghasilkan Spike yang bagus dengan teknik yang benar dan cepat. Dimana hubungan yang positif dan signifikan antara power otot tungkai dengan hasil spike pada cabang olahraga bola voli. Hal ini menunjukan bahwa otot tungkai mempunyai peran penting terhadap hasil spike. Power otot tungkai yang besar akan menghasilkan lompatan yang maksimal. Seorang pemain bola voli sangat diharuskan memiliki lompatan yang setinggi mungkin untuk melakukan spike. Seperti yang dikatakan oleh pakar bola voli bahwa "Pemain-pemain yang menghendaki dapat bermain sebagai penyerang harus mempunyai tenaga yang besar pada kakinya”. Dijelaskan pula oleh Kosasih (1983:118), bahwa "Dalam melakukan spike sebaiknya kita dapat melompat setinggi mungkin, karena itu latihlah melompat sebanyak mungkin". Dengan demikian, dengan otot tungkai yang besar maka seorang spiker akan semakin tinggi menjangkau bola yang diumpankan tinggi diatas net pada saat memukul bola. Adapun dukungan otot tungkai terhadap hasil spike sebesar 0.977.

\section{KESIMPULAN}

Berdasarkan hasil penelitian dan pembahasan, maka didapat kesimpulan sebagai berikut : Terdapat hubungan yang signifikan antara Power otot tungkai (X) terhadap keterampilan Spike. pada siswa bola voli di SMA Negeri 1 Ulu Musi, dengan nilai $\mathrm{r}_{\mathrm{xy}}$ $=0,97>\mathrm{r}_{(0,05)(24)}=0,404$.

\section{SARAN}

1. Bagi pelatih bola voli agar dapat memberikan materi yang tepat untuk melatih keterampilan Spike bola voli sehingga dapat mendukung peningkatan kualitas hasil latihan.

2. Bagi siswa agar dapat mengembangkan keterampilan Spike dalam permainan bola voli dengan menggunakan latihan power otot tungkai.

3. Bagi peneliti yang ingin melanjutkan penelitian ini agar dapat menemukan variabel lain yang dapat memberikan sumbangsih terhadap keterampilan Spike dalam permainan bola voli selain power otot tungkai.

\section{DAFTAR PUSTAKA}

1. Beutelstahl, Dieter. 2015. Belajar Bermain Bola Volley. Bandung: CV. Pionir Jaya

2. Erianti. 2004. Buku Ajar Bola Voli. Padang: Sukabina Press.

3. Hidayat, Witono. 2017. Buku Pintar Bola Voli. Jakarta: Anugrah.

4. IR, Utono. 2010. Ensiklopedia Olahraga Permainan Bola Besar. Semarang: PT Bengawan Ilmu. 
2723-60

5. Lubis, Johansyah. 2013.Panduan Praktis Penyusunan Program Latihan. Jakarta: PT Rajagrafindo Persada.

6. McGinnis, Peter M. 2010. Terjemahan Biomechanics Of Sport And Exercise. Jakarta: UNJ

7. Nawawi, Umar. 2013. Anatomi Tubuh Manusia. Padang: FIK UNP.

8. Nirwandi. 2013. Buku Ajar Anatomi. Padang: FIK UNP.

9. Paturusi, Achmad. 2012. Manajemen Pendidikan Jasmani dan Olahraga. Jakarta: Rineka Cipta

10. Rohendi, Aep dan Etor Suwandar. 2018. Metode Latihan Dan Pembelajaran Bola Voli Untuk Umum. Bandung: Alfabeta.

11. Sarosa, Samiaji. 2017. Penelitian Kualitatif Dasar-Dasar. Jakarta Barat: PT. Indeks.

12. Sepriani, Rika. 2015. Buku Ajar Anatomi Tubuh Manusia. Padang: FIK UNP.

13. Subagyo, P. Joko. 2015. Metode Penelitian Dalam Teori Dan Praktek. Jakarta: Rineka Cipta.

14. Tangkudung, James dan Wahyuningtyas Puspitoroni. 2006. Kepelatihan Olahraga. Jakarta: Cerdas Jaya

15. Undang-Undang RI Nomor 3 tahun 2005

16. Widiastuti. 2017. Tes dan Pengukuran Olahraga. Jakarta: PT Bumi Timur Jaya.

17. Widoyoko, S Eko Putro. 2016. Teknik Penyusunan Instrumen Penelitian. Yogyakarta: Pustaka Pelajar.

18. Yoenoes, Yunan. 2009. Teknik Olahraga Bola Voli. Jakarta: CV. Ipa Abong 